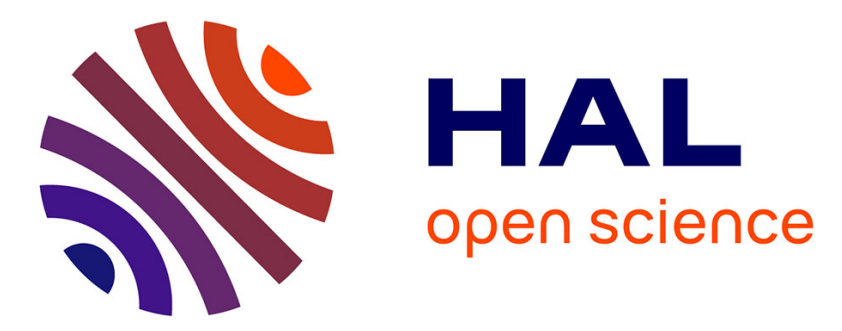

\title{
Characterization of the impregnation by a cementitious matrix of five glass multi-filament yarns
}

Hana Aljewifi, Bruno Fiorio, Jean-Louis Gallias

\section{To cite this version:}

Hana Aljewifi, Bruno Fiorio, Jean-Louis Gallias. Characterization of the impregnation by a cementitious matrix of five glass multi-filament yarns. European Journal of Environmental and Civil Engineering, 2011, 14 (5), pp.529-544. 10.3166/ejece.14.529-544 . hal-00563810

\section{HAL Id: hal-00563810 https://hal.science/hal-00563810}

Submitted on 7 Feb 2011

HAL is a multi-disciplinary open access archive for the deposit and dissemination of scientific research documents, whether they are published or not. The documents may come from teaching and research institutions in France or abroad, or from public or private research centers.
L'archive ouverte pluridisciplinaire HAL, est destinée au dépôt et à la diffusion de documents scientifiques de niveau recherche, publiés ou non, émanant des établissements d'enseignement et de recherche français ou étrangers, des laboratoires publics ou privés. 


\title{
Characterization of the impregnation by a cementitious matrix of five glass multi- filament yarns
}

\author{
Hana Aljewifi — Bruno Fiorio - Jean-louis Gallias \\ Université de Cergy-Pontoise, L2MGC, Institut des matériaux \\ 5 Mail Gay-Lussac, Neuville sur Oise, F-95031 Cergy-Pontoise cedex \\ hana.aljewifi@u-cergy.fr; bruno.fiorio@u_cergy.fr; jean-louis.gallias@u-cergy.fr
}

\begin{abstract}
RÉSUMÉ. Les bétons textiles utilisent comme renfort des fils multifilamentaires dont l'imprégnation par la matrice cimentaire conditionne largement les propriétés mécaniques. Deux méthodes expérimentales qui permettent de quantifier le niveau d'imprégnation du fil sont présentées ici. Ces méthodes ont été testées sur cinq types de fils multifilamentaires de verre, pour trois modes de préparation conduisant à des niveaux d'imprégnation différents. Les résultats des deux méthodes proposées sont mis en parallèle avec la caractérisation qualitative de l'interface fil/matrice réalisée par microscopie électronique à balayage, ce qui permet de faire le lien avec l'imprégnation.

ABSTRACT. Textile reinforced concretes use multifilament yarns as reinforcement. Their mechanical properties are mainly governed by the impregnation of the yarns by the cementitious matrix. Two experimental methods that allow the level of impregnation of the yarn to be quantified are presented. These methods were tested on five different glass yarns, for three preparation methods that induce different level of impregnation. The results are discussed and compared to qualitative characterisation obtained from scanning electronic microscopy, which allows us to link them with the impregnation.

MOTS-CLÉS : fil multifilamentaire, filament, imprégnation, béton textile, écoulement, porosité. KEYWORDS: multifilament yarn, filament, impregnation, textile concrete, flow, porosity.
\end{abstract}

EJECE. Volume $\mathrm{X}-$ no $\mathrm{x} / 2010$, pages 1 to $\mathrm{n}$ 


\section{Introduction}

Textile reinforced concrete (TRC) is a fiber micro-concrete composite material which began to be used about three decades ago. This composite is suitable for many new applications because of its low weight and high load-bearing capacity. It is produced by incorporation of a textile fabric made of oriented continuous yarns into a cementitious matrix. Because of its low thickness, this composite material allows to build reduced weight structural elements, with high strength and ductility (Jesse et al., 2001).

Yarns are constituted from thousands of micrometric filaments (usually ARglass) with filament diameter in the range 10-30 $\mu \mathrm{m}$. These filaments are rather independent one from the other. This specific constitution leads to very specific properties compared to more traditional reinforcement such as steel or composite rods.

The mechanical properties of TRC depend on the mechanical properties of its constituents and on the characteristics of the binding between the yarn and the matrix, which is linked to the way the matrix and the yarn interact. In particular, the specific constitution of yarns induces a partial impregnation by the cementitious matrix. As a consequence, filaments can be separated into two families: sleeve filaments, in the impregnated area of the yarn, and core filaments (Ohno et al., 1994, Langlois, 2004). Sleeve filaments are anchored, when core filaments are not. Mechanical models of the yarn / matrix interaction have to define parameters related to the impregnation level to determine the portion of each of the families of filaments and their contributions to the load (Banholtzer, 2004, Hegger et al., 2003, Langlois et al., 2005). Usually, these parameters are arbitrary defined and it is very difficult to connect them to the physical parameters of the interface.

The research hereafter presented focuses on this last point, and in particular on the matrix / yarn impregnation problematic. It intends to produce quantitative indicators of the impregnation level of the yarn. These indicators could be useful to help to determine the interface parameters used in yarn / matrix interaction modelization. It consists in using two different methods to characterize the porous structure of concrete impregnated multifilament yarns, and in studying the effect of changes in the impregnation level of the yarns on the obtained results.

\section{Specimens characteristics and preparation}

\subsection{Cementitious matrix}

To avoid yarn damaging by coarse aggregates during the manufacturing process, the cementitious matrix used for this study was a micro-concrete made of CEMI 52.5 cement (C) and 0-1.25 mm fine sand (S). A superplasticizer (SP; 64.4\% dry extract 
according to NF P18-380) was used to obtain a high fluidity of the fresh concrete, needed to allow the easy pouring of the cylindrical mould $(3.6 \mathrm{~cm}$ diameter; $25 \mathrm{~cm}$ height). The composition parameters were as follow: $\mathrm{W} / \mathrm{C}=0.5, \mathrm{~S} / \mathrm{C}=1.4, \mathrm{SP} / \mathrm{C}=$ 0.0035. Mixing was made using a standard mortar mixer with respect to the following sequence: low speed dry mixing of solid products $(1 \mathrm{~min})$, low speed mixing with water and superplasticizer $(30 \mathrm{~s})$, final high speed mixing (30 s). Table 1 gives the composition parameters for one batch.

A cement slurry was used in some case to reach a "full impregnation" of the yarn by the cementitious matrix. The mix design was made to obtain the same composition for the cement slurry and the cement paste of the concrete, taking into account the water absorption of the sand (1.10\% according to NF 1097-6). The slurry composition parameters were therefore as follow: $\mathrm{W} / \mathrm{C}=0.48, \mathrm{SP} / \mathrm{C}=0.0035$. Mixing was made using a standard mortar mixer. Table 1 gives the composition parameters for one batch.

\begin{tabular}{lcccc}
\hline & Water & Cement & Sand & Superplasticizer \\
\hline Micro-concrete & $425 \mathrm{~g}$ & $857 \mathrm{~g}$ & $1200 \mathrm{~g}$ & $3 \mathrm{~g}$ \\
Cement slurry & $168.2 \mathrm{~g}$ & $350 \mathrm{~g}$ & $/$ & $1.23 \mathrm{~g}$ \\
\hline
\end{tabular}

Table 1. Micro-concrete and cement slurry composition (per batch).

\subsection{Multifilament yarns}

Five types of glass roving (named in the following OC1, OC2, SG1, SG2 and SG3) have been used in this study. OC rovings are E-glass rovings that came from a first manufacturer, when SG rovings are AR-glass rovings and came from a second manufacturer.

Using E-glass roving was considered as un-problematical, as the work exposed hereafter do not consider long time evolution of the yarn / matrix interaction and is therefore not submitted to durability problems (and in particular to chemical interaction between glass and cement). It should be noted that a sizing covers the surface of the glass filaments. It serves to various functions, depending on the roving (agglomeration of the yarn, protection of the glass, interaction with the matrix,...). Sizing materials are a mix of polyhydroxy-phenols, silane, polymer emulsion and additives. The detailed composition of the sizing is unknown due to the industrial protection imposed by manufacturers.

$\mathrm{OC} 1$ and SG1 to 3 rovings are assembled rovings. OC2 is a direct roving. A direct roving is an assembly of elementary glass filaments. An assembled roving is an assembly of strands themselves constituted from agglomerated elementary filaments. Assembled rovings present a two level structure (filaments / strands) that do not exist in the case of direct rovings.

The main characteristics of the yarns are given in table 2 . 


\begin{tabular}{lccccc}
\hline & OC1 & OC2 & SG1 & SG2 & SG3 \\
\hline Type of glass & $\begin{array}{c}\mathrm{E} \\
\text { Type of roving }\end{array}$ & $\begin{array}{c}\mathrm{E} \\
\text { assembled }\end{array}$ & $\begin{array}{c}\text { AR } \\
\text { direct }\end{array}$ & $\begin{array}{c}\text { ARsembled } \\
\text { assembled }\end{array}$ & $\begin{array}{c}\text { AR } \\
\text { assembled }\end{array}$ \\
Filament diameter $(\mu \mathrm{m})$ & 12 & 17 & 14 & 14 & 14 \\
Fineness $($ tex $=\mathrm{g} / \mathrm{km})$ & 2400 & 2400 & 2450 & 2450 & 3000 \\
Glass density $\left(\mathrm{kg} / \mathrm{m}^{3}\right)$ & 2530 & 2530 & 2680 & 2680 & 2680 \\
Number of filaments & 8385 & 4180 & 5940 & 5940 & 7272 \\
Number of strands & 39 & $/$ & 55 & 30 & 36 \\
\hline
\end{tabular}

Table 2. Characteristics of the multi-filaments yarns.

\subsection{Specimens preparation}

Specimens are cylinders of micro-concrete $(3.4 \mathrm{~cm}$ diameter, $25 \mathrm{~cm}$ height) into which a straight yarn is centered. A specific molding device is used to precisely position the yarn in a cylindrical PVC mold before the casting of the micro-concrete. As the cylinder remains vertical, with the yarn crossing the bottom part of the mold, a specific attention was given to the water-tightness of the mold. In particular, glue was applied on the lower part of the yarn, at the point where it crossed the bottom of the mold. Despite of this care, a small water flow was observed at the bottom level of the yarn, which corresponds to a flow of water along the yarn. Therefore, a $1 \mathrm{~cm}$ layer of water was laid over the micro-concrete after the pouring, to counterbalance the observed water loss and avoid the reduction of the water content of the fresh concrete. Reference specimens, without yarn, are also made. Specimens were removed from mould after $24 \mathrm{~h}$ and then cured to 28 days in $20^{\circ} \mathrm{C}$ water.

One of the three hereafter described pre-treatment was applied to each yarn before putting it into the mould:

- Pre-wetting (W): yarn was saturated with water prior to the casting so that the inter-filaments voids are filled with water, which prevent the cement paste to enter the yarn during casting. It should be noticed that in this case, capillarity forces induce agglomeration of the glass filaments. As a consequence, the inter-filament distances were reduced compared to what is observed in the case of dry yarns.

- Drying (D): yarn was air dried at room temperature before casting. Capillarity leads to penetration of water and cement particles in the yarn when casting. As the filaments act as a filter, penetration of cement particles into the yarn was limited.

- Cement pre-impregnation (PI): the yarn was manually saturated with a cement slurry (table 1) before casting. Saturation was obtained by manual action on the yarn placed in a slurry batch.

Each configuration (type of yarn, pre-treatment) was used to perform different test methods with the aim to characterize the impregnation of the yarn by the matrix. Qualitative information on the impregnation level was obtained from scanning 
electronic microscopy (SEM). This technique also allows the penetration depth of the cementitiuous matrix into the yarn to be roughly estimated.

Two other methods were carried out to characterize the impregnation level by quantitative measurements. One is based on mercury intrusion porosimetry, the other on flow test. These methods give quantitative information related to the impregnation level.

\section{SEM observations}

\subsection{Specimens preparation}

The SEM observations were performed with the aim to characterize the way the impregnation of the yarn by the matrix was made. In particular, specific attention was paid to the homogeneity of the impregnation, and to the existing of different families of filaments, such as core and sleeve filaments. Observation were made after 28 days curing, on longitudinal (parallel to yarn) sections of the micro-concrete specimens. Sections were obtained from split cylinder test performed on $4 \mathrm{~cm}$ long portions of the cylindrical specimens. Complementary information can be obtained from Aljewifi et al. (2009).

\subsection{OC1 yarns}

Figure 1 shows the longitudinal sections obtained for OC1 yarn, for the three different pre-treatments. The pre-wetting of the yarn (W) leads to straight parallel mainly un-impregnated filaments. Conversely, the pre-impregnation with the cement slurry (PI) induces a full impregnation of the yarn, with filaments partially interlocked due to the mechanical action during pre-treatment. Dried yarn (D) shows an intermediate facies, with the main part of the filaments embedded in the matrix, which signifies that the free length of most of the filaments (the distance between two embedded points) is smaller than the length of the specimen $(4 \mathrm{~cm})$.

\subsection{OC2 yarns}

Observations made on $\mathrm{OC} 2$ embedded specimens show that the impregnation pattern is mainly similar to the one observed for OC1 embedded specimens (see figure 2). OC2 $\mathrm{W}$ yarn shows parallel mainly non-impregnated filaments, with a thin layer of impregnated filaments. OC2 D yarn appears as very similar to OC2 $\mathrm{W}$. The main differences are the misaligning of filaments and the appearance of hydrated products in-between filaments in the core filaments. As for OC1 yarn, OC2 PI shows a completely different organization of the yarn with a full impregnation of the filaments by the matrix. In this case, because of the specific structure of the yarn 
(direct roving), the filaments and the matrix are very intimately mixed. No core filaments are detectable and the whole impregnated yarn appears as one homogeneous fibrous body embedded in the micro-concrete.

$\mathrm{W}$

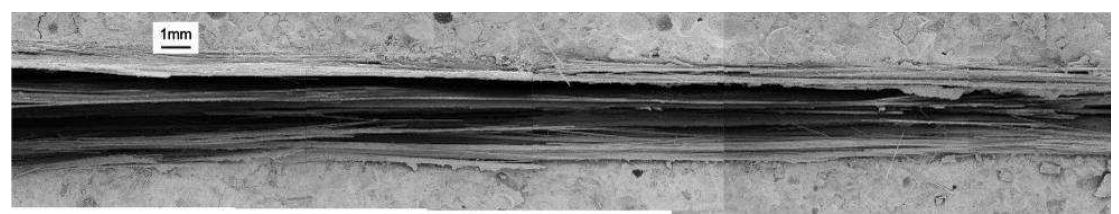

D

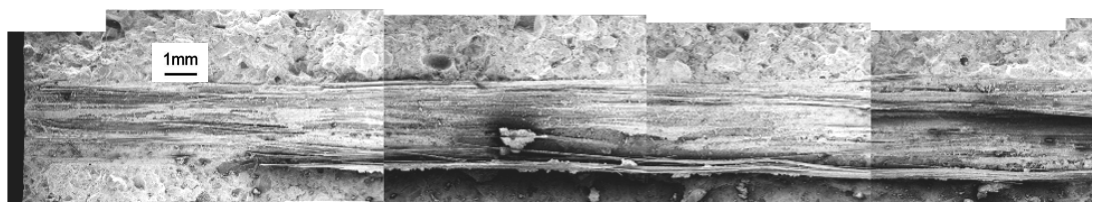

PI

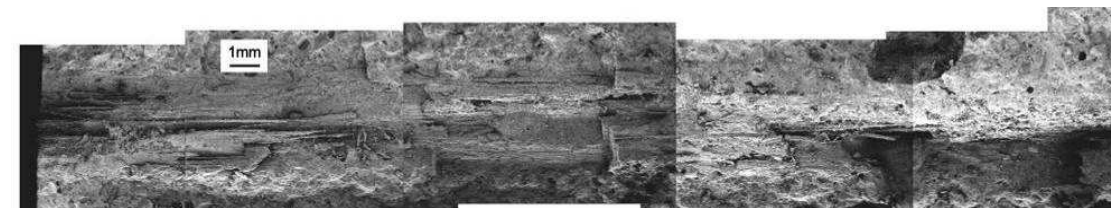

Figure 1. OC1 yarns; longitudinal sections; W, D and PI pre-treatments.

$\mathrm{W}$

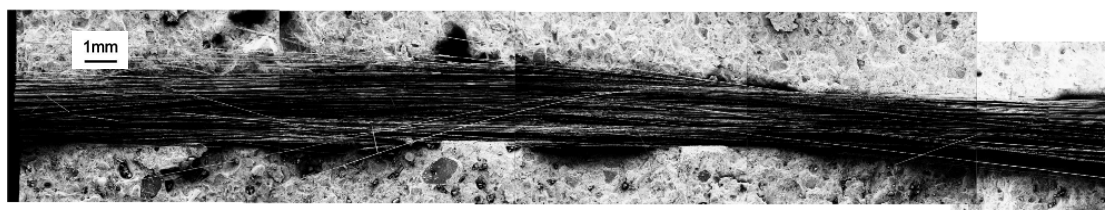

D

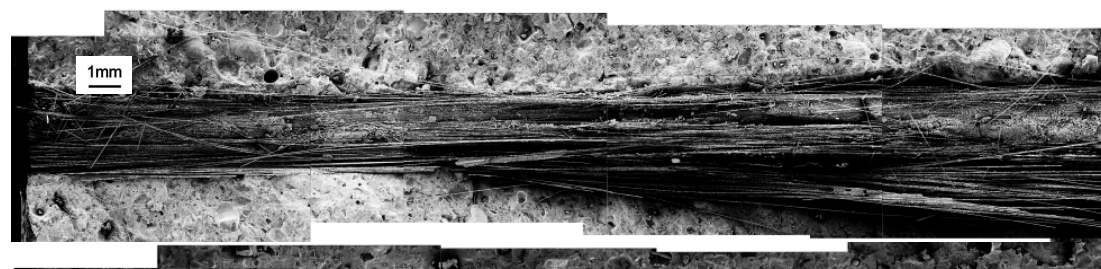

PI

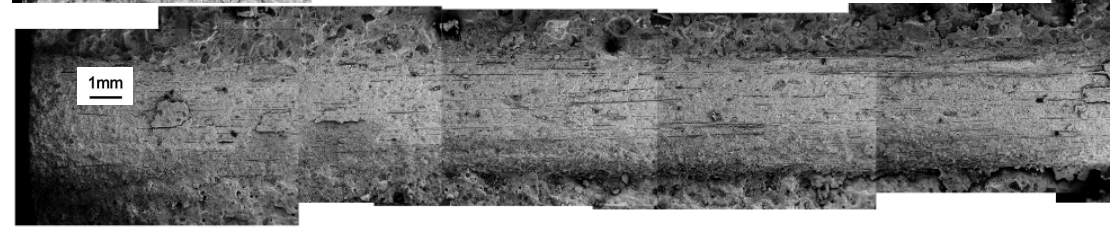

Figure 2. OC2 yarns; longitudinal sections; W, D and PI pre-treatments. 


\subsection{SG1 yarns}

As for OC yarns, the $\mathrm{W}$ pre-treatment leads to a poorly impregnated yarn, with numerous core filaments not in contact with the body of the matrix (figure 3). SG1 D yarn is similar to SG1 W yarn: large portion of the filaments are uncovered by the cementitious matrix. However, in some places the matrix has penetrated the yarn, which leads to pieces of cement paste in which filaments are embedded. SG1 PI yarns appears as fully impregnated by the cementitious matrix. Contrary to OC PI yarns, portions of filaments do not stay embedded in the matrix after splitting of the specimen. It seems that the adhesion of the cementitious matrix to filaments was less important than for OC yarns, which has led to decohesive failure when splitting the sample in two parts before the SEM observation.

\subsection{SG2 yarns}

SEM photographs of OC2 yarns can be seen on figure 4. OC2 $\mathrm{W}$ yarn shows straight parallel mainly un-impregnated filaments. OC2 D yarn is similar to OC2 W yarn, with the exception that matrix agglomerates can be seen inside the yarn, which denotes a partial impregnation, when the pre-impregnation with the cement slurry (PI pre-treatment) has induced a full impregnation of the yarn. These observations make the SG2 yarn to be very similar to the SG1 one, regardless to the relationship between the pre-treatment of the yarn and its impregnation.

W

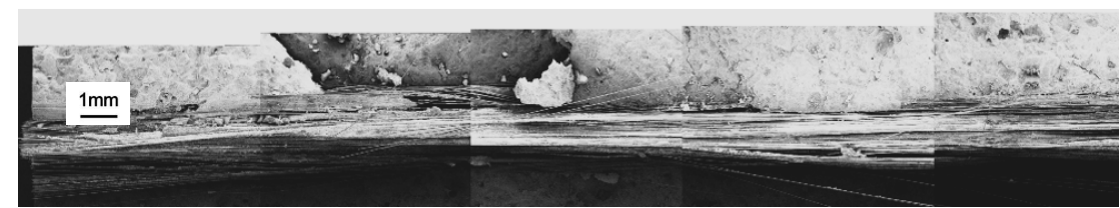

$\mathrm{D}$

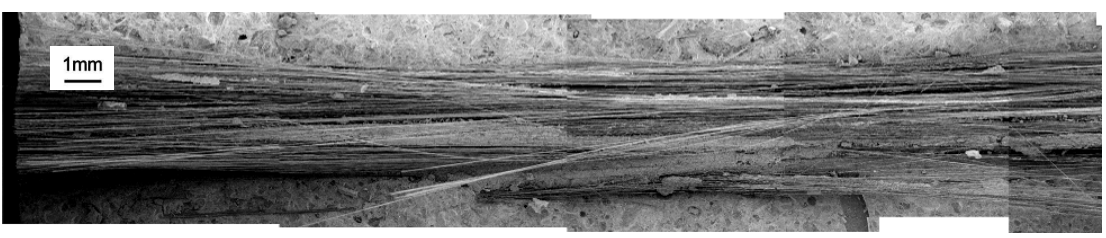

PI

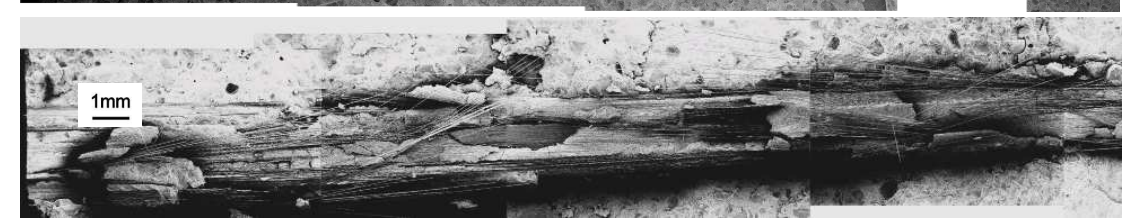

Figure 3. SG1 yarns; longitudinal sections; W, D and PI pre-treatments. 


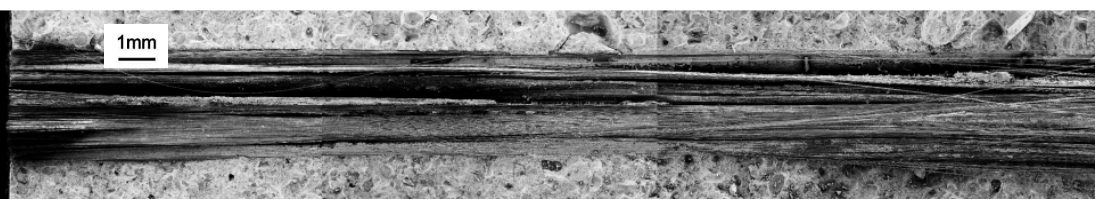

$\mathrm{D}$

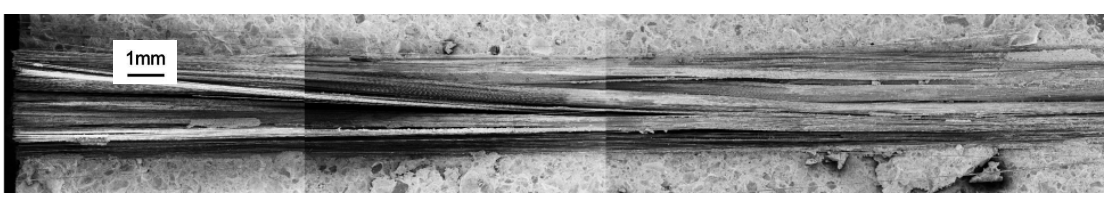

PI

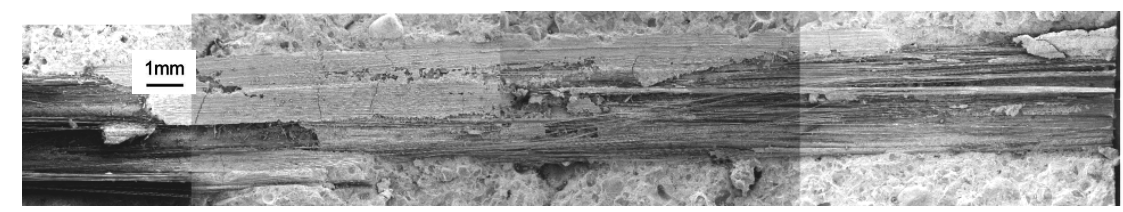

Figure 4. SG2 yarns; longitudinal sections; W, D and PI pre-treatments.

W

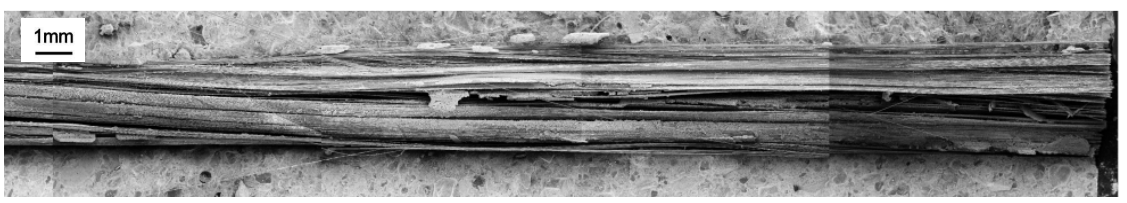

D

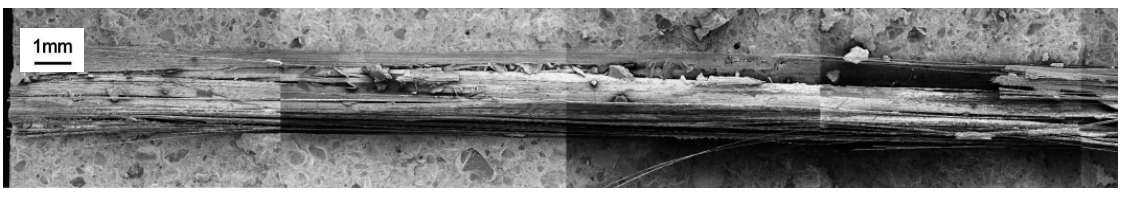

PI

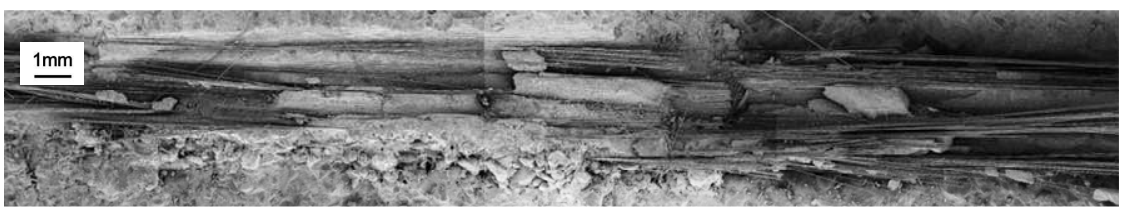

Figure 5. SG3 yarns; longitudinal sections; W, D and PI pre-treatments.

\subsection{SG3 yarns}

SEM photographs of SG3 yarns (figure 5) show much more impregnated yarns than in the case of SG2 yarns prepared with equivalent pre-treatments: SG3 W appears as very close to SG2 D; and SG3 D shows evidences of deep penetration of 
the cementitious matrix inside the yarn. As for other yarns, SG3 PI is fully impregnated.

\subsection{Impregnation of the yarns}

The penetration depth of the cementitious matrix inside the yarns was visually estimated from the SEM observations. Table 3 gives for each type of yarn and impregnation level the diameter of the impregnated yarn and the minimum, average and maximum values of the penetration depth of the cementitious matrix in the yarn.

An impregnation index (named $i_{Y}$ ) is calculated as the ratio of the impregnated area to the apparent area of the cross section of the yarn, with the following assumption: cylindrical yarn, constant penetration depth of the matrix over the perimeter. Taking into account the SEM observations, we assume a full impregnation $\left(i_{Y}=100 \%\right)$ for PI yarns.

Changing the pre-treatment of the yarn (from $\mathrm{W}$ to $\mathrm{D}$ and finally to PI) progressively increases the value of $i_{Y}$ in the case of assembled roving (OC1 and SG yarns). In the case of OC2 yarn (direct roving), $i_{Y}$ is very low and increases only when yarn is submitted to a mechanical action that forces the matrix inside it (figure 6).

\begin{tabular}{lccccc}
\hline Configuration & $\begin{array}{c}\text { Diameter of the } \\
\text { impregnated yarn }\end{array}$ & \multicolumn{3}{c}{ Observed penetration depth $(\mu \mathrm{m})$} & $i_{Y}$ \\
& $(\mu \mathrm{m})$ & & Mverage & Max. & \\
\hline OC1 W & 3520 & 250 & 375 & 500 & $38 \%$ \\
OC1 D & 3260 & 600 & 700 & 800 & $67 \%$ \\
OC1 PI & 4190 & & & & $100 \%$ \\
OC2 W & 2690 & 160 & 170 & 180 & $24 \%$ \\
OC2 D & 3390 & 160 & 170 & 180 & $19 \%$ \\
OC2 PI & 4260 & & & & $100 \%$ \\
SG1 W & 3190 & 100 & 125 & 150 & $15 \%$ \\
SG1 D & 4270 & 300 & 325 & 350 & $28 \%$ \\
SG1 PI & 3220 & & & & $100 \%$ \\
SG2 W & 2841 & 153 & 225 & 321 & $29 \%$ \\
SG2 D & 3141 & 440 & 714 & 1002 & $70 \%$ \\
SG2 PI & 3422 & & & & $100 \%$ \\
SG3 W & 2986 & 487 & 664 & 803 & $69 \%$ \\
SG3 D & 2760 & 1380 & 1380 & 1380 & $100 \%$ \\
SG3 PI & 3090 & & & & $100 \%$ \\
\hline
\end{tabular}

Table 3. Yarns impregnation characterization. 


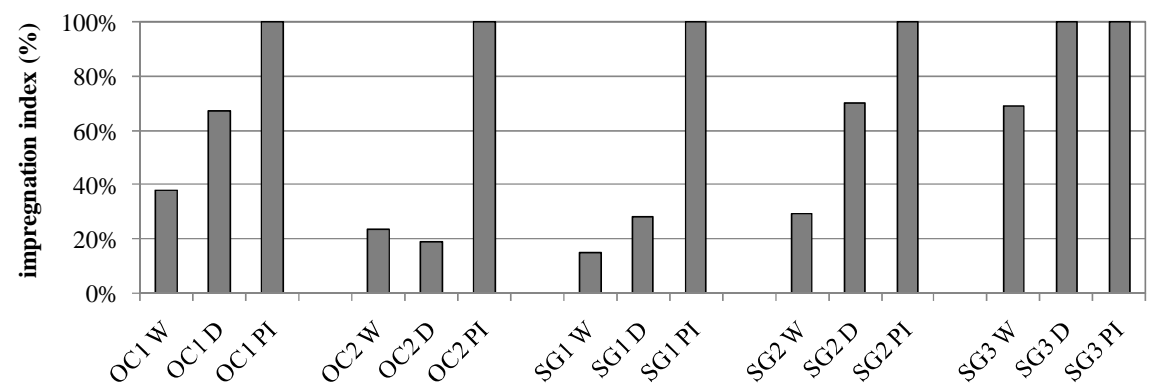

Figure 6. Values of the impregnation index $i_{Y}$ for the different configurations.

\section{Comparative mercury intrusion porosimetry test}

\subsection{Introduction}

This test allows us to evaluate the porosity of a specimen which is specifically associated to the presence of a multifilament yarn (inter-filaments porosity and matrix / yarn interface porosity). To this aim, the pores distribution of the studied specimen (yarn embedded in a cementitious matrix cylinder) is compared to the pore distribution of the corresponding matrix. Pores distributions are determined from mercury intrusion porosity (MIP) tests (Baudouin, 1979; Feldman et al., 1991; Baroghel-Bouny, 1994).

As explained by Aljewifi et al. (2009), the comparison is made in the 0.3 to $3 \mu \mathrm{m}$ range of pores diameter, which distribution is the more able to be impacted by the presence of a yarn. Specimens were $25 \mathrm{~mm}$ diameter mortar cylinder, with a yarn positioned along the cylinder axis. As mercury intrusion porosity measurements are influenced by the size and the geometry of the specimen (Diamond et al., 1993), two configurations were used for the determination of the reference mortar pores distribution: one with a centered $2.5 \mathrm{~mm}$ diameter hole and the second without hole. These two configurations were chosen to approach respectively the percolation of the mercury in a un-impregnated or in a fully-impregnated yarn. The 2.5 hole's diameter was considered as representative of the un-impregnated yarn's diameter. The reference mortar pores distribution is the corresponding average pores distribution.

\subsection{Inter-filaments porosity}

MIP was used to characterize the inter-filament pore range for all configurations. As an example, results for SG1 yarns are given in figure 7. To allow an easy comparison between the different cases, the porosity distribution is reduced to one index, named differential cumulative pore volume $\left(\Delta v_{0.3-3}\right) . \Delta v_{0.3-3}$ is the pore volume 
induced by the presence of the yarn, in the 0.3 to $3 \mu \mathrm{m}$ pore diameter range, for a yarn length of $1 \mathrm{~m}$. It is the difference between the pore volume of the studied specimen and the pore volume of the reference mortar, for a yarn length of $1 \mathrm{~m}$. Pore volumes are determined from the porosity distribution curves by integration between the corresponding values of the pore diameter.

Figure 8 gives the values of the differential cumulative pore volume for all configurations. It should be noticed that, due to the type of measurements made, the accuracy of the results is not important. This is a consequence of the accuracy of the MIP technique and of the choice to compare all specimens to an average reference mortar and not to the specific mortar of each specimen.

However, approximate tendencies can be observed: on average, the lowest values of $\Delta v_{0.3-3}$ are obtained for $\mathrm{W}$ pre-treatment, while the highest values are obtained for PI pre-treatment. The pre-wetting of the yarn (W) tends to induce a compaction of the filaments, due to capillarity forces, whereas the manual introduction of the cement slurry in the yarn (PI) tends to disorganize the filaments and creates voids within the cement slurry coating the filaments. D pre-treatment leads to an intermediary behaviour.

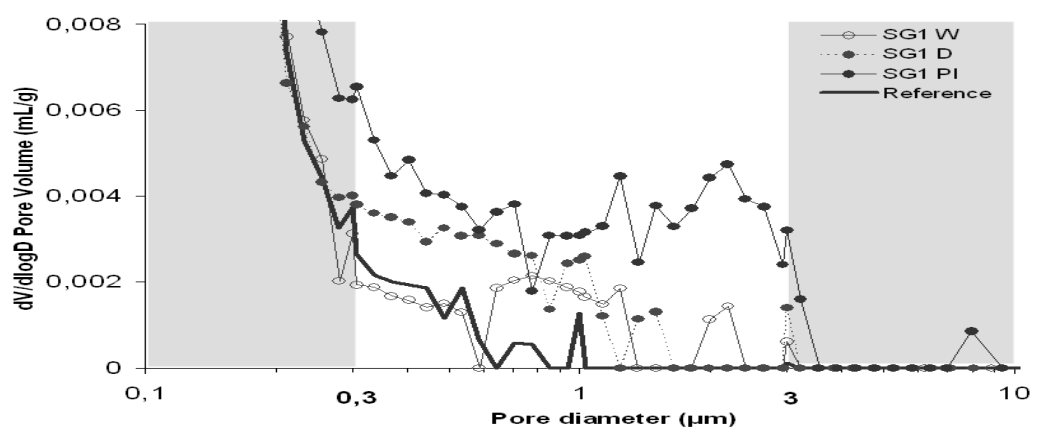

Figure 7. Example of pore distribution for SG1 yarns and mortar reference.

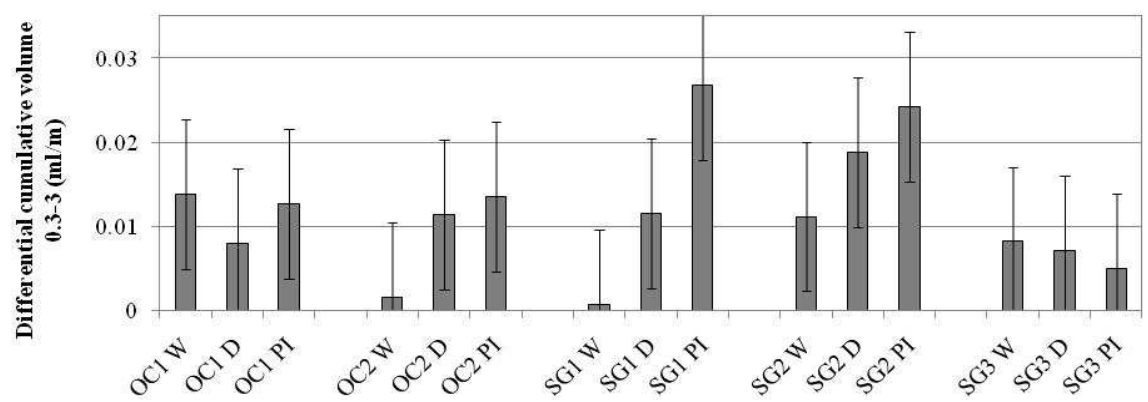

Figure 8. Pore volume induced by the presence of the yarn and accuracy of the measurements. 


\section{Flow test}

Flow test consists in measuring the flow rate of water along an embedded yarn, for an imposed pressure gradient of $1.075 \mathrm{bar} / \mathrm{cm}$. Samples are $2 \mathrm{~cm}$ long portion of the cylindrical specimens described in section 2.3. Two measurements are made in all cases. The flow rate through the mortar body (determined from measurements on reference mortar specimens) is deduced from the measured flow rate through the specimen, which allows the yarn water flow to be precisely calculated. As the size of the yarns varies depending on the type of yarn and pre-treatment used, the flow rate is determined for a $1 \mathrm{~mm}^{2}$ cross section of the impregnated yarns. A graphical presentation of these results is shown in figure 9. The highest flow rates are generally obtained for W pre-treated yarns (only OC1 yarn does not respect this observation), which can be a signature of the connected porosity induced by the mainly unimpregnated parallel multi-filaments structure of the yarns in this case. Despite of their porosity, PI pre-treated yarns give low flow rates, which can be explained by the less connected pores or more tortuous porosity of the mortar that fill the interfilaments voids.

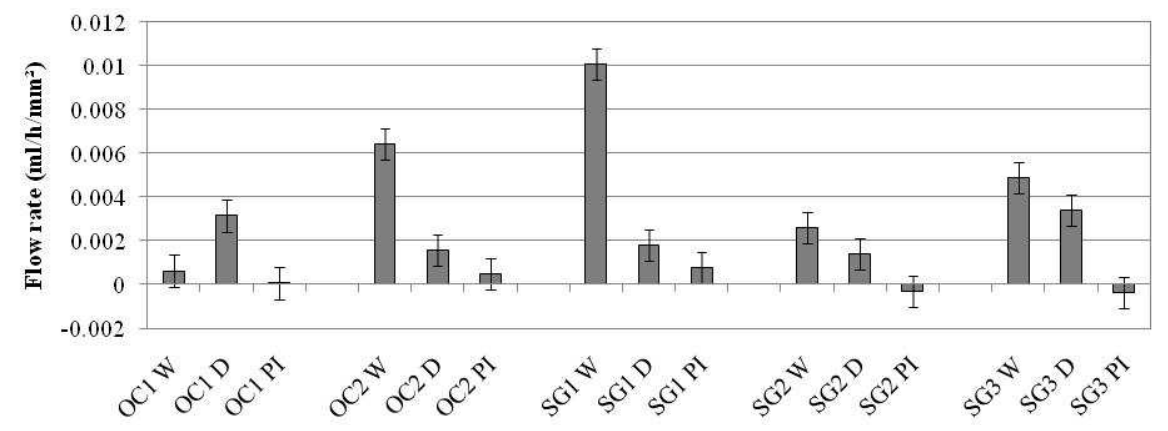

Figure 9. Flow rate along yarns and accuracy of the measurements.

\section{Analysis and discussion}

\subsection{Influence of the impregnation index on the flow rate and on the differential cumulative pore volume}

Figure 10 gives the dependence of the flow rate and of the differential cumulative pore volume to the impregnation index $i_{Y}$. Despite of the moderate precision of the measurements, rough tendencies are observed:

- The flow rate is a decreasing function of the impregnation index. As explained in 5., lowest and highest values of the flow rate respectively correspond to the full impregnated and less impregneted yarns. The sizing, which directly influences the water / filament contact angle, may explain the influence of the type of 
yarn on the high flow rate (direct contact between glass filament and water). On the contrary, the sizing has no major effects on low flow rates, as the water is in this case not in direct contact with the glass filaments.

- The differential cumulative pore volume $\Delta \mathrm{v}_{0.3-3}$ is an increasing function of the impregnation index, except for OC1 and SG3 which give almost constant values. This should be connected to the increasing disorder in the filament arrangement induced by the penetration of the cementitious matrix, especially in the case of PI pre-treated yarns. The presence of cement matrix clusters inbetween the filaments and the filaments crossings that are observed create voids inbetween the cement coated filaments, which increases the pore volume.

These results link the impregnation to the physical properties measured by the mean of flow test and mercury intrusion porosimetry. However, the relationships between these different parameters appear as slightly complex. In particular, the flow rate dependency to the pore volume of the yarn is hard to explain, because it is connected to the pore volume of the yarn and to the diameters of the pores, but also to the type of material in contact with water (mainly glass when the yarn is not impregnated, cement paste when the yarn is impregnated).
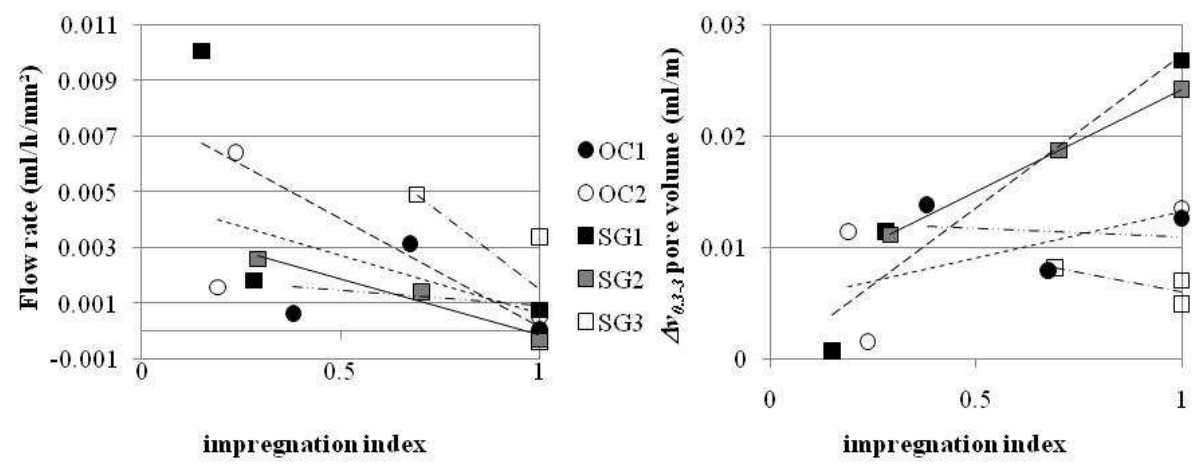

Figure 10. Flow rate (left) and differential cumulative pore volume $\Delta v_{0.3-3} v s$. impregnation index $i_{Y}$.

\subsection{Correlation between flow rate and differential cumulative pore volume}

The relationship between the flow rate and the differential cumulative pore volume shows a good correlation between these two parameters (figure 11). Only the SG3 PI pre-treated yarn badly respects this correlation, but the accuracy of the measurements (figures 8 and 9) can explain the differences. Figure 11 also gives the range of the impregnation index values for each configuration. It can be seen the value of the impregnation index, and therefore the penetration depth of the cementitious matrix inside the yarn, tends to increase when moving from left to right 
on the flow rate / differential cumulative pore volume correlation "curve" (figure 11, grey zone). As a consequence, we think that the use of the flow test and of the comparative intrusion porosity test as a whole could be a good solution to have an approximate quantitative characterization of the impregnation of the yarns, without the need of using SEM observations, which are much more subjected to the partial appreciation of the observer.

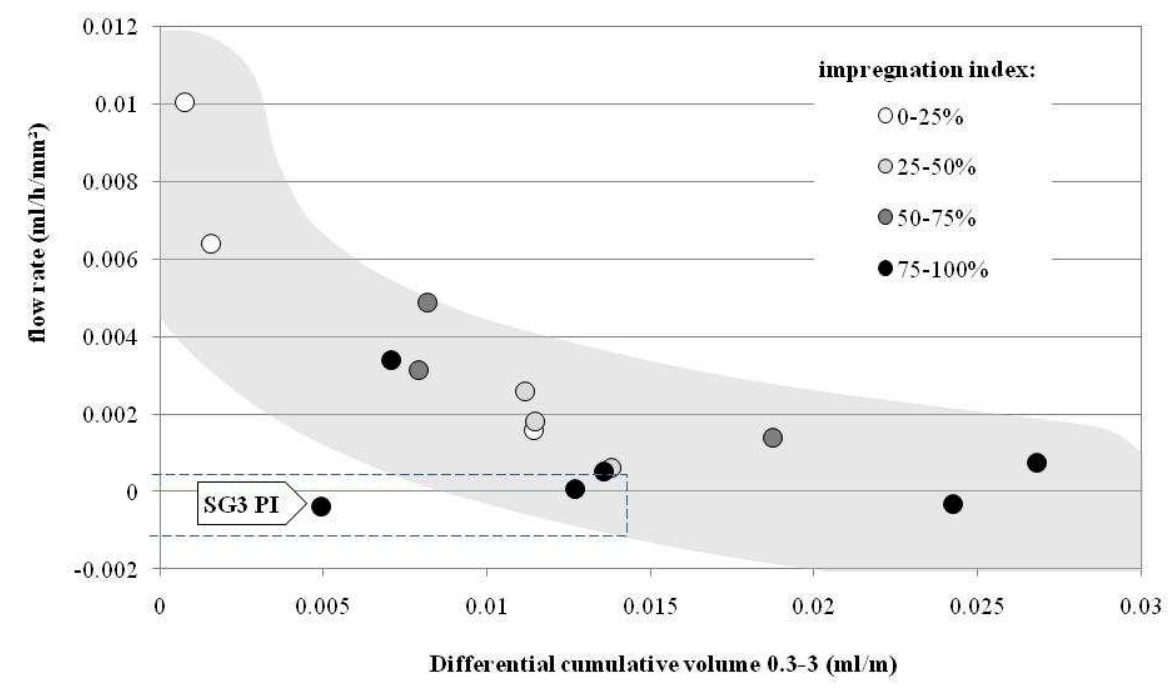

Figure 11. Correlation of flow rate and differential cumulative pore volume $\Delta v_{0.3-3}$ and link to the impregnation index $i_{Y}$.

\section{Conclusion}

The study presented in the previous pages is about the characterization of the impregnation of five multi-filament yarns impregnated by a cementitious matrix. It had two goals. The first was to characterize the five embedded yarns with two dedicated tests able to give quantitative information partially linked to the cementitious matrix impregnation state of the yarn. The second was to link the physical properties measured with these tests to the level of impregnation of the yarns determined from SEM observation.

The main outcome of this study is the correlation of the flow rate measurements to the differential cumulative volume and to the cementitious matrix impregnation. High flow rates are associated to low cumulative pore volumes and appear as characteristic of low impregnation of the yarns. High flow rate results from the organization of the porosity inside un-impregnated yarns: the alignment of the filaments creates thin parallel connected pores that ease the water flow, despite of 
the low value of the pore volume. The intrusion of cement paste in this porosity reduces the connectivity and disturbs the geometrical arrangement of the filaments, which explains the reduced flow rate associated to a highest pore volume.

The comparison between the level of impregnation, estimated from the SEM observation, and the results of the two testing methods allowed us to determine approximate relationships between this two families of data. These relationships are dependent on the type of yarns. The impregnation level can be approximately estimated with the help of the two methodologies, provided that preparatory measurements are made to characterize the behavior of the yarn according to the impregnation process. However, as unstudied parameters may influence the results of the two proposed methodologies, more studies are necessary to refine the relationship between impregnation, flow rate and comparative mercury intrusion porosity measurement to access an acceptable reliability of the estimation of the impregnation. In particular, the study of the surface properties of the glass filaments and their relationship to the way the cementitious matrix introduce in the yarn is necessary to understand the particular role played by the sizing, regardless to the characterization that have been performed.

\section{Acknowledgments}

The authors wish to thank A. Cousture, research engineer at L2MGC, Institut des matériaux, for her contribution to the SEM observations.

\section{References}

Aljewifi A., Fiorio B., Gallias J.L., Quantitative methods to characterize the impregnation of a glass multifilament yarn by a cementitious matrix, 4th Colloquium on Textile Reinforced Structures, June 4-5, 2009, Dresden, Germany.

Banholzer B., Bond behaviour of a multi-filament yarn embedded in a cementitious matrix, thèse, RWTH Aachen University, Germany, 2004.

Baroghel-Bouny V., Caractérisation des pâtes de ciment et des bétons méthodes, analyse, interprétations, thèse de doctorat, Laboratoire Central des Ponts et Chaussées (LCPC) Paris, France, 1994.

Beaudoin J.J., «Porosity measurement of some hydrated cementitious systems by high pressure mercury intrusion-microstructural limitations», Cement and Concrete Research, vol. 9, 1979, p. 771-781.

Diamond S., Bonen D., «Microstructure of hardened cement paste-A new interpretation». $J$ Amer Cer Soc, vol. 76, 1993, p. 2993-2999.

Feldman R.F., Beaudoin J.J., «Pretreatment of hardened hydrated cement pastes for mercury intrusion measurements», Cement and Concrete Research, vol. 21, 1991, p. 297-308. 
16 EJECE. Volume $\mathrm{X}-$ no $\mathrm{x} / 2010$

Hegger J., Bruckermann O., Will, N., «Bond characteristics of multi-filament yarns in a cementitious matrix: Pull-out tests and their numerical simulation», Techtextil-Symposium 2003. 12th International Symposium for Technical Textile, Nonwovens and Textile Reinforced Materials, April 9, 2003, Frankfurt/ Main, Germany, Lecture No. 4.24.

Jesse F., Curbach M., «The present and the future of textile reinforced concrete», In: 5th International Conference on Fibre Reinforced Plastics for Reinforced Concrete Structures, July 16-18, 2001, Cambridge, UK, p. 593-608.

Langlois V., Etude du comportement mécanique des matériaux cimentaires à renforts synthétiques longs ou continues, thèse de doctorat, Université de Cergy-Pontoise, France, 2004.

Langlois V., Beaucour A.L., Cabrillac R., Fiorio B., Gouvenot D., «Study and model of the bond of carbon yarn embedded in a cementitious matrix», 3rd International Congress Composites in Construction, July-11-13, 2005, Lyon, France.

Ohno S., Hannant, D.J.: «Modelling the stress-strain response of continuous fiber reinforced cement composites», ACI Materials Journal, vol. 91, 1994, p. 306-312. 